\title{
Announcing the MMA 2015 Editor's Choice Awards
}

\author{
Ryan M. Deacon ${ }^{1}$
}

Published online: 13 May 2016

(C) Springer Science+Business Media New York and ASM International 2016

I am pleased to announce the manuscripts that have been selected for the 2015 Metallography, Microstructure, and Analysis Editor's Choice award. The authors of these manuscripts are recognized for both the novelty of their research, and for the high quality of their respective manuscripts. These papers exhibit the characteristics that are considered especially important for this journal: clarity of presentation, a proper interpretation and thorough discussion of microstructure, and high-quality micrographs.

These five papers are available "Free Access" through the Editor's Choice link on the MMA website at http:// www.springer.com/materials/special+types/journal/13632, as well as through the journal's page on SpringerLink. Normally, there is a charge for free access, but for papers selected by the editor for this award, the benefit is free.

Study of Coarsening in $\gamma^{\prime}$ Precipitates by Diffusion Couples

C.G. Garay-Reyes, S.E. Hernández-Martínez, J.L. Hernández-Rivera, I. Estrada-Guel, H.J. DorantesRosales, J.J. Cruz-Rivera, R. Martínez-Sánchez Metallogr. Microstruct. Anal. 4(6), 467-474 (2015)

Microstructure and Mechanical Properties of a TRIPAided Martensitic Steel

Koh-ichi Sugimoto, Ashok Kumar Srivastava Metallogr. Microstruct. Anal. 4(5), 344-354 (2015)

Ryan M. Deacon

ryan.deacon@asminternational.org

1 DuPont Engineering Research and Technology, DuPont Co., Experimental Station, E302/117D, P.O. Box 80302, Wilmington, DE 19880-0302, USA

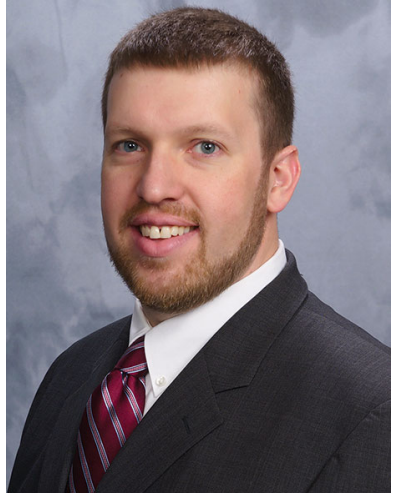

Microstructure and Carburization Detection in HP Alloy Pyrolysis Tubes

A.C. McLeod, C.M. Bishop, K.J. Stevens, M.V. Kral Metallogr. Microstruct. Anal. 4(4), 273-285 (2015)

The Brass Nails of the Akko Tower Wreck (Israel): Archaeometallurgical Analyses

M. Cohen, D. Ashkenazi, Y. Kahanov, A. Stern, S. Klein, D. Cvikel

Metallogr. Microstruct. Anal. 4(3), 188-206 (2015)

Microstructure Characterization of Single and Multipass 13Cr4Ni Steel Welded Joints

Mohsen Mokhtabad Amrei, Yves Verreman, Florent Bridier, Denis Thibault, Philippe Bocher

Metallogr. Microstruct. Anal. 4(3), 207-218 (2015)

Together, these papers highlight the variety of applications where the analysis of microstructure plays a critical role in controlling material performance. From the welding of 
martensitic stainless steels and the development of gammaprime in NiTi alloys, to the analysis of brass nails from a nineteenth century shipwreck, investigating the microstructure enables us to understand, and exploit, material properties.

When I look at the author affiliations for these articles, I see they also underscore the international nature of the journal. Mexico, Japan, India, New Zealand, Israel, Germany, and Canada are all represented in this list of just five articles. I find it encouraging that our journal receives manuscripts from across the globe.
I would also like to take this opportunity to acknowledge all of the authors who have contributed manuscripts to the journal since it began in 2012; your articles are what make this journal possible. One of the benefits of serving as an editor is that each submitted manuscript provides a glimpse into the vast variety of research that is underway in our field. On behalf of the editorial board and journal staff, I thank all of our authors for their fine contributions.

Congratulations again to the 2015 Editor's Choice authors. I look forward to selecting another group of winners from among this year's many excellent submissions. 